\title{
Tensiones entre democracia, soberania y Estado de Derecho: Cajamarca y la consulta popular ${ }^{1}$
}

\section{Tensions Between Democracy, Sovereignty and the Rule of Law: Cajamarca and the Popular Consultation}

\author{
Ana Pabón (iD \\ Universidad Autónoma de Bucaramanga \\ apabon742@unab.edu.co
}

\section{Javier Aguirre (D)}

Universidad Industrial de Santander

jaguirre@uis.edu.co

\section{Juliana Giraldo}

Universidad Santo Tomás de Aquino seccional Bucaramanga julianagiraldotorres@gmail.com

\begin{abstract}
Resumen
El presente texto explora cuatro enfoques teóricos de la democracia contemporánea, así como las críticas que se formulan desde los autores más recientes a cada uno de estos, en especial desde el modelo agonístico. Estos desarrollos teóricos se pueden tomar como referentes para analizar la tensión que en el sistema político y jurídico colombiano se vive alrededor de las consultas populares frente a la adjudicación de titulos mineros. Para abordar este escenario se tendrá como referente el caso del municipio de Cajamarca. Este artículo es producto de un análisis teórico - deductivo en el que se analizan fuentes documentales a partir de la hermenéutica crítica. El principal resultado del análisis del caso de Cajamarca es comprender la tensión que plantean los enfoques de la democracia agonística y las críticas a los modelos liberales de democracia formal.
\end{abstract}

Palabras Clave: Democracia, soberanía, estado de derecho, consulta popular, minería.

\section{Abstract}

The present text explores four theoretical approaches to contemporary democracy as well as the critiques that are formulated from the most recent authors to each one of them, especially from the agonistic model. These theoretical developments can be taken as references to analyze the tension in the Colombian political and legal system around

$1 \quad$ El presente texto es resultado del proyecto de investigación titulado "Las nociones de democracia que subyacen en la jurisprudencia de la Corte Constitucional colombiana, comprendida en el período 1998-2015, referida a la protección de los derechos fundamentales de los estudiantes ante las medidas sancionatorias - pedagógicas contenidas en los manuales de convivencia en las instituciones escolares". Este proyecto es adelantado por el grupo de investigación Politeia de la Escuela de Filosofía de la Universidad Industrial de Santander (UIS) y el grupo de investigación en Teoría del Derecho y formación jurídica de la Universidad Autónoma de Bucaramanga (UNAB). 
popular consultations on the adjudication of mining title to deal with this scenario, the emblematic case of the municipality of Cajamarca will be taken as a reference. The article is the product of a theoretical-deductive analysis, in which documentary sources are analyzed based on critical hermeneutics. The main result of the analysis of the Cajamarca case is to increase the understanding of the tension raised from the theory by the approaches of agonistic democracy and the criticisms of the liberal models of formal democracy

Key Words: Democracy, sovereignty, rule of law, popular consultation, mining.

Articulo: Recibido el 20 de noviembre de 2018 y aprobado el 23 de febrero de 2019.

\section{Cómo citar este articulo}

Pabón, A., Aguirre, J. \& Giraldo, J. (2019). Tensiones entre democracia, soberanía y Estado de Derecho: Cajamarca y la consulta popular. Reflexión Politica 21(41), pp. 36-48. DOI: https://doi.org/10.29375/01240781.3444

\section{Introducción}

En Cajamarca, Tolima, se realizó una consulta popular con el fin de decidir sobre la explotación de oro en el municipio, así como sucedió en otros lugares de Colombia. Esta consulta se usó como un recurso de la población para impedir la ejecución del proyecto de una multinacional minera. El resultado de la consulta, que alcanzó una amplia votación, fue que el 97\% de los votantes se manifestó en contra de la explotación minera en el municipio. Pese a dicho resultado, el ejecutivo central señaló que la decisión de la población era "una decisión política que, aunque manifiesta la voluntad popular de sus habitantes, no tiene la capacidad de cambiar la ley” (El Espectador, Redacción Nacional, 27 de Marzo de 2017)²

Ante la reacción del ejecutivo, la población anunció que, si era necesario, optaría por la desobediencia civil y las vías de hecho con el fin de que se respetara la voluntad de las mayorías expresada en la consulta.Este conflicto se puede analizar desde lo que Chantal Mouffe (2003) denomina la paradoja de la democracia liberal, entendida como la tensión que surge entre las tradiciones democrática y liberal; tensión que aún no ha logrado resolverse. La tensión surge alrededor de los valores que se sobreponen para cada una de estas visiones.

Para la tradición democrática, la participación y la soberanía deben ser las bases de una sociedad justa, de ahí que sean principios clave "la igualdad, la identidad entre gobernantes y gobernados y la soberanía popular" (Mouffe, 2003, p. 19). Esto podría traer como consecuencia la subordinación de los derechos de libertad e igualdad individuales. En la tradición liberal, por su parte, lo que prima es el imperio de la ley y la defensa de los derechos individuales como la libertad e igualdad, lo que en ocasiones hace difícil configurar una unidad política colectiva. (Mouffe, 2003, p. 19)

La tensión que se genera radica en que las democracias liberales han terminado imponiendo límites sumamente rígidos a la soberanía popular, con el fin de garantizar los derechos y el imperio de la ley, generando con ello fricciones de todo tipo e, incluso, creando malestares y desmotivación en relación con la democracia misma.

El caso de Cajamarca ilustra muy bien esta tensión, la cual también puede entenderse a la luz de uno de los problemas más fuertes que ha reconocido la filosofía política y del derecho contemporáneo, a

2 La multinacional ya tenía un título minero legalmente válido para iniciar labores, a pesar de que le faltaba la licencia ambiental. Sin embargo, pese a la consultar popular, podía continuar con el procedimiento administrativo para lograr el permiso. La consulta popular fue valorada como una 'decisión política', que obligaría al Concejo municipal y a la Alcaldía a implementar restricciones en su Plan de Ordenamiento Territorial (POT) para el futuro pero no limitaría el trámite de la multinacional. Para el representante del Ejecutivo "Este mecanismo de participación ciudadana no tiene la capacidad de cambiar el Estado Social de Derecho, es decir, de alterar los equilibrios de los poderes entre el Ejecutivo, el Legislativo y las Cortes. Me refiero a que esta es una consulta, localizada en un municipio, donde se expresó la voluntad de las comunidades y que tiene el poder de darles una orden a su alcalde y a su concejo municipal, pero 6.100 personas no tienen la capacidad de romper el Estado Social de Derecho. Aquí quien define el manejo legal de esto es el Congreso de la República". (El Espectador, Redacción Nacional, 27 de Marzo de 2017) 
saber, las relaciones problemáticas entre facticidad y validez, o, para ser más precisos, entre legitimidad y legalidad.

Esta tensión debe entenderse, además, en el contexto contemporáneo en donde las sociedades se caracterizan por la diversidad, lo que en ocasiones se traduce en sociedades fragmentadas por intereses antagónicos en las que no se logra llegar a acuerdos mínimos (Mejía, 2016, p. 47).

Esta realidad exige reflexionar acerca del paradigma teórico que permitiría proponer un camino de acción para superar dicha tensión, o por lo menos comprenderla mejor, con el fin de reconfigurar los ideales de la democracia contemporánea. Esta reflexión se realiza desde uno de los roles propuestos por Rawls (2002) para la filosofía política, la cual, según el filósofo estadounidense, "puede contribuir al modo en que un pueblo considera globalmente sus instituciones políticas y sociales, y sus objetivos y propósitos básicos como sociedad con historia” (p. 24).

Entre los intentos por proponer una alternativa al modelo liberal de democracia encontramos las tesis de Rawls y Habermas, cuyas propuestas son una apuesta por superar la tradición liberal y fundar una visión de democracia consensual o deliberativa. De otra parte, también existe un buen grupo de autores que rechazan radicalmente la tradición liberal y que consideran insuficiente la respuesta de la democracia deliberativa. En este grupo están, especialmente, las perspectivas de Mouffe y Laclau ${ }^{3}$.

El abordaje de la propuesta deliberativa se puede entender desde la pregunta de Rawls (1995) “¿cómo es posible que pueda existir a través del tiempo una sociedad estable y justa de ciudadanos libres e iguales profundamente dividida por doctrinas religiosas, filosóficas y morales, razonables, aunque incompatibles entre sí?” (p. 13). Pregunta que resaltaba el carácter altamente plural de los ciudadanos y ciudadanas en las sociedades contemporáneas. Sin embargo, el papel asignado a los ciudadanos desde el paradigma deliberativo fue fuertemente criticado, entre otros, por Nancy Fraser, para quien esta concepción terminó consolidando una esfera pública burguesa, que dejó por fuera a muchos sectores de la población, (negros, mujeres, campesinos, entre otros), quienes tuvieron que configurar escenarios cuyas relaciones con el público burgués eran de naturaleza conflictiva.

La democracia debe garantizar la participación amplia e integrar a la ciudadanía (Mejía, 2016); la propuesta de Rawls y Habermas ha sido valorada como una apuesta hacia este objetivo; sin embargo, autoras como Fraser (1997) señalan que en la práctica dicho modelo es insuficiente para alcanzar la participación de todos los sectores de la sociedad, lo cual ha obligado a que se generen otras formas de incidencia. Es el caso de los contrapúblicos entendidos como "espacios discursivos paralelos donde los miembros de los grupos sociales subordinados inventan y hacen circular contradiscursos, lo que, a su vez, les permite formular interpretaciones opuestas de sus identidades, intereses y necesidades" (1997, p. 115). Esta supuesta incapacidad del modelo deliberativo para que toda la ciudadanía tenga voz y sea incluida es lo que suscita la formulación de tesis, como las de Mouffe, que proponen otras formas de ejercicio de democracia en las que, más allá de alcanzar un consenso, se valoren los desacuerdos existentes y quizá insolubles.

El presente artículo tiene como problema central el abordaje de la pregunta por las nociones de democracia que se pueden encontrar en los principales debates de la filosofía y la teoría política contemporánea en relación con las posibilidades que estas nociones tienen para facilitar la comprensión de las tensiones entre participación política y Estado de Derecho en casos como el de Cajamarca descrito anteriormente. Se trata entonces de discutir, en relación con un caso concreto, la fuerza explicativa de ciertas concepciones de democracia. Es por esto que para el desarrollo del problema de investigación propuesto se acudió, en términos metodológicos, a un "estudio de caso dirigido por la teoría” (Simons, 2009, p. 45).

Para dar respuesta a dicha cuestión, se caracterizan las principales nociones de democracia y las posturas críticas sobre los distintos modelos teóricos. Como punto de partida se realizó una indagación teórica, a partir de la revisión de fuentes

3 Nancy Fraser podría verse como un puente entre estas dos vertientes. Pueden verse: Fraser N, (2006). La justicia social en la era de la política de la identidad: Redistribución, reconocimiento y participación, En: N. Fraser, A. Honneth, ¿Redistribución o reconocimiento?, Ediciones Morata, Madrid; Fraser, N. (1993). Repensar el ámbito público: una contribución a la crítica de la democracia realmente existente. Debate feminista, 23-58. Recuperado de http://www.debatefeminista.com/PDF/ Articulos/repens1080.pdf; Fraser, N. (1997). Iustitia interrupta. Reflexiones críticas desde la posición postsocialista, Bogotá: Siglo del Hombre 
documentales con base en pautas de análisis documental, siguiendo los lineamientos de la hermenéutica crítica. La revisión del componente teórico se abordó partiendo de la premisa de que en sociedades como las latinoamericanas, el ideal de democracia deliberativa sigue siendo un ideal en construcción ${ }^{4}$, y que propuestas como la agonística han ido tomando fuerza como alternativas viables para comprender mejor nuestras dinámicas socio - políticas, ante la imposibilidad de los modelos existentes de legitimar el sistema político.

Se parte entonces de la revisión de los modelos liberal, republicano, deliberativo y agonístico y se tiene como caso paradigmático la tensión vivida en el Municipio de Cajamarca, Colombia. Este caso es relevante para la discusión, pues integra los elementos que desde el enfoque teórico reconstruido caracterizan la tensión entre democracia, soberanía y Estado de Derecho frente al conflicto por la explotación minera: por un lado, la población (que encarna la soberanía como poder constituyente) reclama que su voluntad sea tenida en cuenta, mientras que, por su parte el poder ejecutivo, como poder constituido, defiende la legalidad y competencia formal en la toma de decisiones. La metodología del estudio de caso dirigida por la teoría, nos lleva a comprender mejor las tensiones alrededor del ejercicio de la democracia a partir de la relación que postulamos entre las categorías de análisis con los hechos principales del caso.

La revisión del caso propuesto resulta pertinente, pues cuando el Ejecutivo afirma que la decisión de Cajamarca es política y que se impone el Estado (Social) de Derecho, está tomando partido por la tradición liberal, dejando a los ciudadanos de Cajamarca frente a un déficit de legitimidad y de cara a otros mecanismos para reclamar su soberanía popular como ideal democrático, lo que evidencia la tensión entre soberanía y Estado de Derecho. La reconstrucción del caso se realizó a partir del análisis de las fuentes documentales publicadas en los distintos medios de divulgación periodística, informes de organismos del Estado y de pronunciamientos oficiales del Estado Colombiano.

Para presentar los resultados de la reflexión, producto de investigación, se hace una descripción analítica del marco teórico, posteriormente se caracterizará el caso que sirve como referente de análisis, y finalmente se presentan algunas conclusiones de la reflexión en las que se evidencian las conexiones explícitas entre el marco teórico y el análisis del caso concreto.

\section{Modelos de democracia: de la democracia liberal a la democracia agonistica}

En la filosofía política contemporánea existe una gran cantidad de clasificaciones de la democracia; no obstante, en toda esa variedad, se destacan cuatro modelos que han sido desarrollados con cierto detalle y, especialmente, en el contexto de un debate por cuál de ellos puede responder mejor a los retos de las sociedades contemporáneas. Estos modelos son el liberal, el republicano, el deliberativo (o consensual) y el agonístico. En lo que sigue describiremos cada uno de estos enfoques.

\section{a. Una democracia de tipo liberal}

Este modelo se caracteriza por "la limitación del poder del Estado mediante la ley y el reconocimiento de los derechos fundamentales" (Touraine, 2000, p. 46). Para Mouffe (2003), la democracia liberal enfatiza fuertemente la sujeción al impero de la ley y la defensa de los derechos individuales. Habermas, por su parte, lo caracteriza en los siguientes términos:

Según la concepción liberal, este proceso democrático cumple la tarea de programar al Estado en interés de la sociedad, entendiéndose el Estado como el aparato que es la administración pública y la sociedad como sistema del tráfico de las personas privadas y de su trabajo social, estructurado en términos de economía de mercado. La política (en el sentido de la formación de la voluntad política de los ciudadanos) tiene la función de agavillar e imponer los intereses sociales privados frente a un aparato estatal que se especializa en el empleo administrativo del poder político para conseguir fines colectivos. $(2005, \mathrm{p} .1)$

Desde esta perspectiva, Habermas (2005)

$4 \quad$ Investigaciones previas dan cuentan de la forma en que los debates acerca de cuestiones divisivas en el contexto colombiano se alejan de la propuesta de Habermas o Rawls. Ver Aguirre, J., Silva, A., Pabón, A. (2016). Habermas y el rol de la religión en la esfera pública: El caso de las intervenciones ciudadanas en la Sentencia C-355-06. Vniversitas, 113(23), 2358.; Pabón, Ana, (2017) Liberalización de la interrupción voluntaria del embarazo: propuesta desde la democracia consensual, Universidad Libre: Bogotá. 
coincide con Touraine y Mouffe al mostrar que la democracia liberal es la representación de una jurisdicción orgánica, que bien puede ser representada en la división de poderes, que de manera paralela cohabita con el interés privado, libre y desconcentrado representado en el mercado.

Este modelo es la representación de la garantía de derechos liberales individuales (la tradición reivindicada por las revoluciones burguesas) y la sujeción al principio de legalidad. Este modelo acarrea una visión particular del ciudadano como sujeto de derechos limitado por el orden jurídico y con herramientas jurídicas para controlar el poder del Estado.

\section{b. Una democracia de tipo republicano}

Touraine (2000) la define como aquella en la que se le da mayor relevancia a la ciudadanía y existe una mayor orientación hacia la igualdad y el bien común. En Mouffe (2003) se encuentra referida a la tradición democrática que está fundada en la igualdad e "identidad entre gobernantes y gobernados y soberanía popular" (p. 20). Para Habermas 2005, por su parte, "en la concepción republicana el espacio público político y, como infraestructura suya, la sociedad civil, cobran un significado estratégico pues tienen la función de asegurar a la práctica del entendimiento entre los ciudadanos su fuerza integradora y su autonomia” (p. 2).

En vez de la división de poderes, la autonomía del mercado y la primacía de los derechos individuales, un modelo republicano enfatiza la solidaridad y el bien común, con el fin de que no prime, como en el modelo liberal, la voluntad privada únicamente. Se da un paso hacia la búsqueda del bien común y la prevalencia de la idea de la soberanía popular. Es así que:

La jurisdicción de la existencia del Estado no radica primariamente en la protección de iguales derechos subjetivos privados, sino en que garantiza un proceso inclusivo de formación de la opinión y la voluntad políticas, en el que ciudadanos libres e iguales se entienden acerca de qué fines y normas redundan en interés común de todos. Con eso a los ciudadanos republicanos parece estárseles pidiendo bastante más que una mera orientación por sus intereses privados. (Habermas, 2005, 2).

Ahora bien, ¿en qué radica la insuficiencia de estos dos modelos? Touraine señala que la separación de poderes entendida como un elemento esencial de la democracia, termina confundiendo la organización del poder con su limitación. Desde esta perspectiva es insuficiente, y hasta inadecuado, hablar de separación de poderes, cuando se trata no de las relaciones entre diferentes centros de decisión dentro de la sociedad política, sino de la puesta frente a frente del Estado y los derechos fundamentales, y por lo tanto de una limitación mucho más que de una separación de poderes. (2000, p. 49).

La democracia liberal, incluso en su versión "participativa”, termina desconociendo el papel de la ciudadanía, en la medida en que las élites que ostentan la representación terminan imponiendo "sobre la ciudadanía y el conjunto de sujetos colectivos que la componen, los procedimientos, los contenidos y productos jurídicos de asuntos de su directa incumbencia sobre los cuales aquella no es estructuralmente tenida en cuenta" (Mejía, 2016, p. 48).

Desde la perspectiva de Touraine (2000) el modelo liberal que da origen al Estado de Derecho, al dar primacía a la garantía de los derechos (garantía formal) termina separando el orden político jurídico de la vida social, en tensión con la soberanía popular que subordina la vida política a la forma en que se relacionan los actores sociales. Esta tensión o paradoja también fue identificada por Mouffe, para quien "lo que no puede ser objeto de discusión en una democracia liberal es la idea de que es legitimo establecer límites para la soberanía popular en nombre de la libertad. De ahí su naturaleza paradójica” (2003, p. 22).

Ahora bien, frente al modelo republicano debe anotarse que sus desventajas se centran en el tipo de ciudadano que requiere y en la definición de lo que es el bien común. Habermas señala que como modelo

(...) es demasiado idealista y (...) hace depender el proceso democrático de las virtudes de ciudadanos orientados al bien común. Pero la política no se compone sólo, y ni siquiera primariamente, de cuestiones relativas a la autocomprensión ética de los grupos sociales. El error consiste en un estrechamiento ético de los discursos políticos. (2005, p. 4)

El modelo precisa ciudadanos razonables, éticos y virtuosos, lo cual puede distar de la realidad en muchos casos. Por otra parte, la definición del bien común no es una tarea fácil, se podría correr el 
riesgo de que a fuerza de la voluntad de las mayorias se imponga una forma de bien común que deje por fuera valores, intereses y aspiraciones de las minorías que no logran participar en la definición de la idea de bien común.

\section{c. La democracia deliberativa o consensual}

La propuesta de Habermas y Rawls es valorada como una alternativa a los dos modelos descritos; su propuesta consensual - deliberativa le da un mayor papel a la ciudanía y a la esfera pública, con el fin de garantizar la legitimidad de las instituciones y del sistema democrático, mediante procedimientos de deliberación ciudadana y de consenso, en rechazo a la democracia de mayorías que tiene un carácter más plebiscitario. Así ha sido valorado por Mejía Quintana, para quien, en este modelo, se entiende a la ciudadanía:

Como factor estructural en la concepción, elaboración, ejecución y control de los procedimientos, contenidos y productos jurídicos que regulan una sociedad. El poder comunicativo de la sociedad civil deviene así en poder administrativo, siendo la voluntad popular traducida a normas legales que interpretan, a través de los canales institucionales, su posición política sobre los asuntos que la afectan. (2016, p. 48)

¿Qué elementos caracterizan la propuesta de la democracia consensual? Para Rawls, la concepción política de la justicia se logra mediante el consenso de ciudadanos libres e iguales, aunque profundamente divididos por sus distintas doctrinas comprensivas razonables. Las ideas de consenso entrecruzado y de razón pública de Rawls se ofrecen como los elementos que permiten alcanzar los acuerdos sobre la concepción de justicia. Un régimen democrático requiere para su supervivencia de la unión de sus ciudadanos pese a que "profesan muy diversas y opuestas, aunque razonables, doctrinas comprensivas" (Rawls, 1995, p. 58). Naturalmente los ciudadanos están profundamente divididos por distintas concepciones, lo cual supone que para garantizar la estabilidad de la sociedad "la concepción de justicia que se afirme en una sociedad democrática bien ordenada debe ser una concepción limitada a lo que llamaré ‘el dominio de lo político' y a los valores que preconiza” (Rawls, 1995, p. 59).

Este modelo se diferencia del modelo liberal formalista, se propone como mecanismo para garantizar la unidad y estabilidad de una sociedad bien ordenada, pese a los intereses individuales de los ciudadanos.

El consenso se construye a partir de un proceso de debate $\mathrm{y}$ argumentación, incluyente $\mathrm{y}$ transparente, pues "las personas tienen concepciones diferentes e inconmensurables del bien, de forma que la unidad de cooperación social se basa en una concepción pública de la justicia que garantiza las libertades básicas” (Rawls, 1990, p. 121).

El consenso se logra, primero, mediante un acuerdo constitucional que fijará las reglas y acuerdos que permitirán pasar al consenso entrecruzado. En este nivel se define el contenido de la concepción política de justicia, los bienes primarios y libertades básicas. "En el consenso constitucional, una constitución que satisface ciertos principios básicos establece procedimientos electorales democráticos para moderar la rivalidad política dentro de la sociedad" (Rawls, 1995, p. 168).

Una vez se ha logrado el consenso constitucional se pasa al consenso entrecruzado. Este consenso se construye mediante la discusión política, en donde se pueden presentar distintas tesis razonables sobre las cuestiones objeto de deliberación a través de argumentos de razón pública. La discusión en la esfera de la razón pública permite garantizar la legitimidad de los acuerdos.

En el caso de Habermas (2006) su propuesta parte de la legitimación que se alcanza a partir de la conciliación entre la acción comunicativa propia del mundo de la vida y los subsistemas político y económico; conciliación alcanzada por la conexión que se logra de todo lo anterior a través de un derecho anclado en el poder comunicativo de la sociedad civil y la esfera pública.

El procedimiento democrático permite institucionalizar las formas de comunicación de forma tal que todos los afectados por una decisión o por la creación de una regla puedan participar del proceso de deliberación previo a su adopción (y criticarla una vez fuera adoptada). Este procedimiento debe su legitimación a dos componentes:

(...) por un lado, a la participación política igualitaria de los ciudadanos, que garantiza que los destinatarios de las leyes puedan también entenderse a sí mismos al mismo tiempo como los autores de esas leyes; y, por otro lado, a la dimensión epistémica de las formas de discusión y de 
acuerdo dirigidas deliberativamente, que justifican la presunción de resultados racionalmente aceptables. (Habermas, 2006, p. 128)

El modelo de Habermas se propone como un intento por incluir los elementos valiosos de la tradición liberal y republicana, restableciendo los elementos de la legitimidad fracturada en las sociedades contemporáneas.

\section{d. La democracia conflictiva o agonistica}

Touraine se refiere a la democracia conflictiva, como aquella que insiste más "en la representatividad social de los gobernantes" y en la defensa de los intereses populares (2000, p. 46). Este modelo es representado en la propuesta de Mouffe y Laclau quienes critican no sólo la tradición liberal, sino los intentos de la democracia deliberativa por superar la paradoja entre libertad e igualdad, pues estos autores consideran que

no hay duda de que las soluciones que proponen son distintas, pero comparten la creencia de que a través de los adecuados procedimientos deliberativos debería ser posible superar el conflicto entre los derechos individuales y las libertades, por un lado, y las demandas de igualdad y participación popular por otro. (Mouffe, 2003, p. 25)

Para Mouffe el consenso es insuficiente; el pluralismo, como rasgo de la democracia contemporánea, hace necesario valorar el disenso y el antagonismo, puesto que "en una organización política democrática, los conflictos y las confrontaciones, lejos de ser un signo de imperfección, indican que la democracia está viva y se encuentra habitada por el pluralismo" (2003, p.50).

La defensa de la tradición liberal por la garantía de las libertades y del modelo republicano por garantizar la participación política parece insuficiente por separado. La primera por su inclinación procedimental hacia las mayorías y la segunda porque su arraigo a "la noción de "bien común", no parece ser lo suficientemente sensible para atender el pluralismo y multiculturalismo de las sociedades modernas" (Aguirre \& Botero, 2014, p. 69).

Para Mouffe, a la larga, la perspectiva deliberativa no se aparta del paradigma liberal, de hecho, el modelo deliberativo puede entenderse como un intento por rescatar las fortalezas del modelo liberal y republicano, superando sus debilidades. (Aguirre \& Botero, 2014)

Pese a que el paradigma deliberativo reconoce la pluralidad de valores e intereses de las personas libres e iguales y no persigue un consenso global (en asuntos religiosos, morales o filosóficos), sino, desde la perspectiva de Rawls (1995), un consenso entrecruzado de doctrinas comprensivas razonables, la visión agonística considera que este paradigma no se toma suficientemente en serio el hecho del pluralismo. De ahí que los defensores del modelo agonístico afirmen que "la primera obligación de la política democrática no consiste en eliminar las pasiones de la esfera de lo público para hacer posible el consenso racional, sino en movilizar esas pasiones en la dirección de los objetivos democráticos" (Mouffe, 2003, p. 116).

En lo que sigue se analizará la discusión acerca de la democracia en el contexto colombiano, primero en términos normativo - jurídicos parar luego describir los elementos del caso propuesto, y de ahí pasar al análisis de las tensiones que muestra el modelo de la democracia agonística.

\section{La democracia como derecho fundamental en Colombia: un sentido normativo desde la jurisprudencia y la doctrina}

En el contexto jurídico colombiano, es posible caracterizar la democracia como un derecho de rango fundamental desde dos ámbitos: desde el análisis a partir de la doctrina y la teoría sobre los derechos fundamentales, y desde la interpretación que se ha dado a las normas constitucionales referidas a la democracia y a la participación.

En la literatura nacional se identifican autores que contribuyen al desarrollo de la democracia como derecho fundamental. Es el caso del profesor Chinquilla (2009), quien afirma que los derechos fundamentales son aquellos derechos humanos que cumplen "dos requisitos esenciales: a) el reconocimiento explícito o implícito en textos constitucionales vigentes, y b) para su defensa han sido blindados con el máximo nivel de garantías reforzadas (institucionales, sustantivas y judiciales) que el derecho positivo hoy puede otorgar" (p.104); y Caldera $(2011,2017)$, cuya tesis concluye que la democracia es un derecho autónomo tutelable.

De igual forma, autores como Robert Alexy (1993) y Luigi Ferrajoli (2016) han desarrollado 
ampliamente teorias que permiten afirmar que la democracia es un derecho fundamental. De acuerdo con el primero de ellos, un derecho es fundamental si tiene una estructura tripartita, en la cual se identifique el sujeto titular del derecho, el sujeto pasivo, a quien se le impone el deber de actuar o de abstenerse, y, en tercer lugar, el objeto del derecho.

Por su parte, Ferrajoli (2016) plantea que los derechos fundamentales tienen las siguientes características:

1. Una estructura universal, que no limite la tutela del derecho.

2. Lograr una igualdad, de forma que el derecho puede ser atribuible a cualquier persona, en virtud de ese estatus.

3. Una naturaleza supranacional, de manera que el derecho fundamental a la democracia no esté sometido a fronteras territoriales.

4. Deben corresponderle unas garantías jurídicas propias.

La Constitución Política de 1991 en su artículo primero señaló que Colombia es una República "democrática, participativa y pluralista" (Const., 1991, art. 1); en el tercero dispuso sobre la soberanía que está "reside exclusivamente en el pueblo, del cual emana el poder público. El pueblo la ejerce en forma directa o por medio de sus representantes, en los términos que la Constitución establece" (Const., 1991, art. 3). Siguiendo este derrotero, el constituyente incorporó mecanismos para la garantía efectiva del ejercicio de la soberanía y del derecho a la participación democrática al incorporar los mecanismos de participación ciudadana como instrumentos para el ejercicio directo de la soberanía, así se indica en el Capítulo IV en donde se consagran "formas de participación del pueblo en ejercicio de su soberanía”, entre las que se encuentra la consulta popular.

Pese a que en el caso colombiano, en la Constitución Política de 1991 no se encuentra exegéticamente consagrado que la democracia es un derecho fundamental, desde la teoría de los derechos fundamentales de los autores mencionados, y desde la interpretación que se ha construido en la jurisprudencia de la Corte Constitucional, se han consolidado precedentes que sustentan esta tesis.

La Corte Constitucional, como intérprete de la Constitución, ha determinado que el núcleo esencial de la democracia como derecho fundamental es la participación, como elemento inherente al ejercicio del derecho a la democracia (Sentencia T-587 de 2001). Ahora bien, ¿este desarrollo normativo es suficiente para la garantía del derecho a la democracia? Las garantías formales de los derechos son un buen ejercicio de democracia liberal, identificar si estos derechos abstractos en efecto logran materializarse o hacer seguimiento a su ejercicio permite construir otras percepciones sobre las tensiones que surgen a la hora de materializar su disfrute.

En principio el Estado Colombiano incorpora un modelo de democracia, lo que debe resolverse es qué modelo teórico permite comprender mejor la forma en que se materializan dichos enunciados.

En lo que sigue se mostrarán elementos de la tensión entre la participación democrática como un ejercicio de soberanía y las otras reglas del Estado, como expresión de la democracia liberal, tensiones que se pueden visibilizar en el caso de Cajamarca.

\section{Democracia, soberania y Estado de Derecho: las tensiones y los dilemas fácticos que se evidencian en el caso de Cajamarca}

En el Municipio de Cajamarca, en el departamento del Tolima, Colombia, los habitantes hicieron uso de la Consulta Popular, mecanismo constitucional de participación ciudadana que convoca a la población a las urnas, para que mediante votación se manifiesten sobre un asunto de interés local o nacional, con el fin de expresar su postura frente a la actividad minera que venía realizándose desde 2009 por parte de la multinacional AngloGold Ashanti, a través del proyecto de extracción de oro La Colosa.

Desde el 2014 se había consolidado la iniciativa popular que buscaba que el Alcalde presentara ante el Concejo Municipal una propuesta de Consulta Popular. Sin embargo, desde esta primera iniciativa, el ejecutivo central promovió acciones legales para frenarla (Hincapié, 2017, p 92). Es así como se expidió el Decreto 2691 del 23 del 2014 que dota de autoridad al Ministerio de Minas para tomar decisiones en proyectos mineros. Por su parte la Procuraduría General de la Nación, en cabeza de Alejandro Ordoñez, presionó "a los concejales municipales de Cajamarca con el fin de impedir la realización de la Consulta Popular, la cual finalmente fue negada por el Concejo" (Hincapié, 
2017, p 92) en febrero de 2015.

Pese a estos obstáculos, finalmente la movilización social contra la minería logró adelantar todos los trámites legales para la realización de la Consulta Popular; el 26 de marzo de 2017, el 97.9\% de la población de Cajamarca votó en contra de la presencia de actividad minera en su territorio, al responder a la pregunta: ¿Está de acuerdo, sí o no, con que en Cajamarca se ejecuten proyectos y actividades mineras?

Tras este resultado, se vieron enfrentadas nuevamente la legitimidad de la voluntad popular, manifestada a través de la Consulta Popular como mecanismo de participación, y la legalidad de las actuaciones administrativas previas que se habían surtido en el desarrollo del proyecto, tales como licencias ambientales, entre otras ${ }^{5}$.

Una vez la población se manifestó, el principal cuestionamiento que surgió giró en torno a la materialización efectiva del resultado de la Consulta Popular, por parte del Estado y de las autoridades encargadas de ejecutar la voluntad de los votantes como responsabilidad derivada de un mandato constitucional que consagra al pueblo como constituyente primario.

De acuerdo con la Ley estatutaria 1757 de 2015, que regula el derecho a la participación democrática, el resultado de la Consulta Popular es de obligatorio cumplimiento y debe ser materializado por parte del órgano competente, dentro del mismo período de sesiones o a más tardar en el período siguiente. (Ley 1757, 2015). La decisión de la consulta es un mandato de rango constitucional. No obstante, tras un año de la realización de la Consulta, el Concejo Municipal, como autoridad competente para expedir un acuerdo que regule la materia, no se había pronunciado al respecto, pues muchas reglas de rango legal imposibilitaban formalmente el cumplimiento del mandato soberano.

El resultado de la votación de la Consulta Popular suscitó diversas reacciones, tanto por parte de los residentes del Municipio, como por parte del Estado. Desde el comienzo del proceso que culminó con el rechazo de la actividad minera, la comunidad del Municipio de Cajamarca se mostró confiada y firme en su decisión, a pesar de las consecuencias que se generarían en la economía de la región.

La postura del poder constituido se evidenció principalmente bajo la vocería del entonces Ministro de Minas y Energía, Germán Arce, quien afirmó que "el resultado no puede romper el Estado social de derecho" (Revista Semana, 2017) ${ }^{6}$. En este mismo sentido manifestó ante otros medios de comunicación, que:

La consulta minera en Cajamarca no tiene la capacidad de cambiar la ley (...) no tiene el poder de hacerse retroactiva, es decir, de invalidar decisiones tomadas hacía atrás (...) Esta decisión, de orden político, no tiene la capacidad de afectar un procedimiento administrativo que todavía no se ha adelantado.

Este mecanismo de participación ciudadana no tiene la capacidad de cambiar el Estado Social de Derecho, es decir, de alterar los equilibrios de los poderes entre el Ejecutivo, el Legislativo y las Cortes. Me refiero a que esta es una consulta, localizada en un municipio, donde se expresó la voluntad de las comunidades y que tiene el poder de darles una orden a su alcalde y a su concejo municipal, pero 6.100 personas no tienen la capacidad de romper el Estado Social de Derecho. Aquí quien define el manejo legal de esto es el Congreso de la República (El Espectador, 2017, 27 de marzo).

En este mismo sentido, la profesora de la Universidades de los Andes y del Externado, Margarita Ricaurte (Revista Portafolio, 2017, 27 de marzo), experta en derecho minero, sostuvo que la consulta popular "Es una opinión y las autoridades podrán considerarla, pero el principio de participación no es competencia para decidir" (Revista Dinero, 2017, 3 de marzo).

Al respecto es relevante mencionar que

$5 \quad$ El Decreto 0934 de mayo de 2013 establece en su artículo primero que "La decisión de establecer zonas excluidas y restringidas de minería compete exclusivamente, y dentro de los límites fijados en los artículos 34 y 35 de la Ley 685 de 2001 , a las autoridades minera y ambiental, quienes actuarán con base en estudios técnicos, económicos, sociales y ambientales y dando aplicación al principio del desarrollo sostenible" y luego en el parágrafo primero del mismo artículo señala que "los Concejos Municipales y las Asambleas Departamentales no podrán establecer zonas del territorio que queden permanentemente o transitoriamente excluidas de la minería mediante acuerdos municipales u ordenanzas departamentales respectivamente, por exceder el ámbito de sus competencias". Sin lugar a dudas como lo señala la profesora Hincapié (2017, p. 91) el decreto busca frenar los efectos de las Consultas Populares en materia de minería.

$6 \quad$ Esta posición ya había sido expresada por el entonces presidente Juan Manuel Santos, cuando al referirse a las Consultas Populares indicó que: "esas consultas son ilegales y no tienen ningún efecto legal. El subsuelo es de todos los colombianos. Aquí no hay lugar a discusión." (El Espectador, 21 de diciembre de 2013). 
precisamente el resultado de un mecanismo de participación ciudadana, en este caso la Consulta Popular, es la manifestación de la voluntad del constituyente primario, razón de ser del Estado y su estructura. Por ende, si sólo se ve como la opinión de un número determinado de personas, y no como ejercicio del derecho fundamental de participación, se estaría negando la potestad que tiene el ciudadano de participar e incidir sustancialmente en las orientaciones del Estado del cual es parte. Es decir, el desconocimiento del resultado de la Consulta Popular efectuada en Cajamarca conlleva una alteración del orden democrático y la negación del Estado Social de Derecho, en cuanto desconoce la naturaleza misma del poder constituyente primario: el pueblo como único soberano.

Como lo afirman Garcés y Rapalino (2015)

Más que el tema minero lo que está en juego es la esencia del Estado Social de Derecho, pues si los ciudadanos no pueden adoptar decisiones sobre su entorno debido a los intereses económicos de la nación (sic) los valores y fundamentos de la carta política de 1991 habrían desaparecido. (p. 61)

En consecuencia, el derecho de participación no sólo implica decisión, sino autodeterminación del orden jurídico por el que el pueblo quiera regirse. Pero esto se entiende mejor si se conectan estas reflexiones con los modelos democráticos descritos anteriormente. Esto es lo que pasamos a hacer a continuación.

\section{A manera de conclusión: democracia, soberania y Estado de Derecho: las tensiones y los dilemas teórico - politicos que se evidencian en el caso de Cajamarca}

La reflexión que se presentó giró en torno a la indagación acerca de qué concepciones teóricas sobre la democracia permiten comprender mejor la tensión entre participación política, soberanía y Estado de Derecho en casos como el de Cajamarca y las consultas mineras.

El modelo liberal muestra una férrea defensa de la supremacía de la ley y la democracia formal. Las afirmaciones del Ejecutivo en el caso de Cajamarca y la regulación mediante decretos acerca de quiénes son las autoridades para la toma de decisiones en materia minera son una muestra de la prevalencia del modelo liberal en su imaginario, pues se defienden los intereses económicos señalando como soporte el principio de legalidad, en desmedro de los derechos de participación de la comunidad directamente afectada con la aplicación de la ley, incluso sobre la constitución y su interpretación. El modelo liberal se muestra insuficiente para orientar la toma de una decisión en este caso, pues no elimina el problema estructural y promueve un descontento generalizado con la noción misma de democracia. En otras palabras, el modelo liberal corre el riesgo de destruirse a sí mismo.

El modelo republicano tampoco permite comprender esta tensión, pues bajo la idea de que la minería representa la satisfacción del bien común y la protección de los intereses generales del país, se intenta desconocer a las comunidades directamente afectadas con la extracción minera y sus propias ideas de bien común. El bien común se entiende como un modelo de desarrollo económico, en particular "la locomotora minera", pero, ¿existen otras formas de desarrollo económico alternos? Los defensores de modelos de desarrollo sostenible, sustentable y humano están convencidos de que el bien común se puede lograr por otros medios, que reconozcan las particularidades de las comunidades y que integren sus sabes ancestrales y sus formas de sostenimiento económico ${ }^{7}$. La idea del bien común, como se observa es muy ambigua; $\mathrm{y}$, en efecto, se puede señalar que "el bien común" que prima es el de todos los colombianos, no solo el de Cajamarca. Pero entonces hay varios "bienes comunes", y el modelo republicano no parece sensible a esto ni permite ofrecer una respuesta que concilie las distintas nociones de bien común.

El modelo deliberativo parecería ofrecer una alternativa de solución. Sin embargo, se torna demasiado exigente a la hora de pensar en discusiones, diálogos y consensos bien llevados. En el caso Cajamarca hay demasiadas acciones estratégicas en juego. Incluso, se corre el riesgo de rechazar las consultas porque "no se delibera lo suficiente" o "no se delibera lo suficientemente bien". Desde ahí, las críticas de los tecnócratas centralistas que señalan que las personas consultadas no están bien informadas, son ignorantes, que el diálogo no se da, etc., aparecerían reforzadas. No obstante, vale la pena

$7 \quad$ Puede verse Sen, A. (1998). Bienestar, justicia y mercado, Barcelona, Ediciones Paidós Ibérica, y Sen, A. (2000). Desarrollo y libertad, Barcelona, Ediciones Planeta. 
plantear la siguiente pregunta: ¿quienes toman decisiones que afectan a una comunidad realmente conocen la población, sus intereses, dinámicas, formas de vida, prioridades, cosmovisión?, ¿Estas formas de vida importan a la hora de definir el bien común y de llevar a cabo deliberaciones rigurosas? En ocasiones puede suceder que desacreditar a un votante en una consulta popular porque no está bien informado parta de una concepción particular sobre el saber que debe primar, ese saber que permitirá entender cuál es la idea de bien común. Es en este punto en donde el modelo deliberativo muestra su mayor debilidad, pues los diálogos y el consenso pueden girar en torno a la idea particular de bien común o de público ilustrado con ciertos saberes y no todas las partes pueden tener la misma capacidad o fuerza para que su posición sea tenida en cuenta. Vale la pena recordar la crítica de Fraser (1997) según la cual, a la larga, los modelos deliberativos de democracia terminan creando "una esfera pública burguesa", una esfera de expertos en donde públicos como los campesinos y sus saberes no son tenidos en cuenta en la esfera real de la discusión.

Ante las dificultades que tienen estos modelos para comprender y dar salida a la tensión en un caso como este, vale la pena analizar el problema de Cajamarca desde el modelo agonístico, modelo que reporta una ventaja: permite mostrar y validar la lucha, el desacuerdo, las diferencias entre los intereses de "la nación" y "los pueblos", los intereses de gobiernos central y gobiernos locales, los modelos de desarrollo en pugna, los intereses de las multinacionales y de los ciudadanos. Además, permite evidenciar también que el debate centralismo - federalismo que acompañó toda la historia del siglo XIX aún está vigente; y permite leer que al final no se trata de Estado de Derecho, ni de Derecho únicamente, sino que en ocasiones los intereses económicos pesan más que la voluntad popular, pues la definición del bien común no siempre está guiada por los destinatarios directos de las decisiones.

Para el caso objeto de análisis, la consulta popular representa un ejercicio de participación y como tal materializa el ejercicio del derecho a la democracia en términos de la primacía de la soberanía popular, pues se trata de un mecanismo constitucional previsto para la manifestación de la voluntad del constituyente primario, que cuenta con disposiciones legales que regulan su vinculatoriedad y en donde lo que permitiría completar su ejercicio sería la voluntad política del poder constituido, quien debería asumir la decisión del soberano como un mandato de obligatorio cumplimiento. Todo esto, se repite, es validado teóricamente desde una teoría agonística de la democracia.

El desprecio por los resultados de la Consulta Popular en el caso de Cajamarca, y la falta de voluntad política para materializar el mandato del poder soberano, permiten leer la tensión entre soberanía y Estado de Derecho como una pugna de visiones de democracia, lo que finalmente le da razón a las críticas de Mouffe (2003) contra el modelo liberal, ya que queda en evidencia la falta de idoneidad de la consulta como un mecanismo formal para el ejercicio del derecho fundamental a la democracia.

$\mathrm{Si}$ bien es cierto, la democracia como derecho fundamental requiere la existencia de garantías plasmadas en la Constitución Política, no es suficiente que las garantías se incluyan en una norma positiva, si el núcleo axiológico del derecho queda desprotegido, puesto que se hace nugatorio el derecho. En cambio, la idoneidad de las garantías del derecho fundamental a la democracia, dependen de que se tutele de manera efectiva el ejercicio del derecho de participación y de que el Estado asuma las cargas que le corresponden como consecuencia de la protección del derecho, tanto de naturaleza jurídico política, como económica. De lo contrario, resulta incongruente defender un ideal de democracia sustantiva, si se mantienen condicionamientos formales a las respuestas que se dan al ejercicio de las garantías (Giraldo, 2018).

Finalmente, en el Municipio de Cajamarca se suspendieron las actividades mineras, pero la suspensión no fue producto de la consulta, sino de la decisión de la compañía multinacional de suspender sus labores de exploración en la zona. Lo anterior evidencia que si bien los habitantes de Cajamarca veían hecho realidad su deseo de eliminar la extracción de oro de su territorio, esto no se dio como resultado de la materialización efectiva de su voluntad popular sino de los intereses económicos de la compañía, quien perdió interés en el proyecto. Un año después, los habitantes de Cajamarca reconocen que se ha afectado el empleo y se han suspendido proyectos de desarrollo de infraestructura que adelantaba la compañia multinacional. Sin embargo, no se arrepienten de su decisión y aseguran que ese territorio "es una 
despensa agrícola que siempre ha funcionado sin minería. Lo que se necesita es un gobierno que impulse esa vocación para que sea cada vez más próspera” (Revista SEMANA, 2018, 26 de marzo). El sentimiento de esta comunidad muestra la diversidad de ideas de bien común, y cómo la garantía de la voluntad del soberano debería ser tenida en cuenta sobre los intereses protegidos por el Estado de Derecho, cuyas garantías formales van más allá del texto de la ley.

Ahora bien, el debate no se ha cerrado. Recientemente la Corte Constitucional decidió que las consultas populares no pueden frenar proyectos mineros, pese a que se han realizado nueve consultas populares ${ }^{8}$ en donde ha ganado el 'no' de la ciudadanía. El Tribunal reiteró que la decisión en materia minera le compete al Estado, pues es el propietario del subsuelo. Para Róbinson Mejía, integrante del Comité Ambiental de Cajamarca, la sentencia "desconoció sus propias jurisprudencias" y advirtió que al "quitar la posibilidad de resolver los conflictos de manera democrática, los ciudadanos acudirán a las vías de hecho”. (El tiempo, 2018). Desde nuestro punto de vista queda por analizar qué tipo de democracia subyace en esta controvertida decisión de la Corte.

Es probable que ir más allá del derecho e identificar los valores y conflictos en pugna pueda dar mayores luces para comprender este problema; sin embargo, aunque el modelo agonístico permite comprender la tensión, no es muy claro qué camino debe tomarse para resolverla.

\section{Referencias}

Aguirre, J., \& Botero, D. (2014). De Habermas a Dussel: 1o político como un elemento crucial de la teoría democrática. Reflexión política, 16(32), 58-72.

Aguirre, J., Silva, A., \& Pabón, A. (2016). Habermas y el rol de la religión en la esfera pública: $\mathrm{El}$ caso de las intervenciones ciudadanas en la Sentencia C-355-06. Vniversitas, 113(23), 23-58.

Alexy, R. (1993). Teoría de los derechos fundamentales. Madrid, España: Centro de Estudios Constitucionales.

Así está Cajamarca luego de su 'no' rotundo a la minería de oro. (26 de marzo de 2018. Revista Semana SOSTENIBLE. Recuperado de https:// sostenibilidad.semana.com/impacto/articulo/ cajamarca-tolima-le-dice-no-a-la-mineria-y- no-se-arrepiente/39755

Caldera, J. (2017). La democracia: un derecho fundamental desde la doctrina de la integralidad en los derechos fundamentales y el enfoque basado en los derechos humanos o la democracia integral D+EBDH. (Tesis Doctoral). Universidad Santo Tomás, Bogotá, Colombia.

Caldera, J. (2011). La democracia como derecho fundamental. Una aproximación dogmática desde el garantismo. Universidad Santo Tomás, Bogotá, Colombia.

Chinchilla, T. (1999). ¿Qué son y cuáles son los derechos fundamentales? Bogotá: Temis.

"Claves del fallo sobre consultas para frenar actividades extractivas" (12 de octubre de 2018). EL TIEMPO. Recuperado de: https://www. eltiempo.com/justicia/cortes/corteconstitucional-dice-que-consultas-minaresno-pueden-frenar-la-mineria-280304

Congreso de Colombia. (06 de julio de 2015) Ley estatutaria. Por la cual se dictan disposiciones en materia de promoción y protección del derecho a la participación democrática. [Ley 1757 de 2015]. DO: 49565.

"Consulta minera en Cajamarca no tiene la capacidad de cambiar la ley": Gobierno. (27 de marzo de 2017). EL ESPECTADOR. Recuperado de: https: / /www.elespectador.com/noticias / nacional/consulta-minera-en-cajamarcano-tiene-la-capacidad-de-cambiar-la-leygobierno-articulo-686515

Corte Constitucional de Colombia. (07 de junio de 2001) Sentencia T-587. [M. P. Alfredo Beltrán Sierra]

Constitución política de Colombia [Const.] (1991). Segunda edición. Gaceta Constitucional No. 116 de 20 de julio de 1991. Recuperado de http://www.secretariasenado.gov.co/senado/ basedoc/constitucion_politica_1991.html

En Cajamarca se tomarían vía Panamericana si gobierno no respeta resultado de consulta popular. (26 de septiembre de 2017). RCN Radio. Recuperado de http://www.rcnradio.com/nacional/encajamarca-se-tomarian-via-panamericana-sigobierno-no-respeta-resultado-de-consultapopular/

Ferrajoli, L. (2016). La democracia constitucional. En Carlos Arturo Hernández y Santiago Ortega Gomero (Eds). Derechos fundamentales, democracia fundamental y garantismo. (92181) Bogotá: Universidad Libre.

Fraser, N. (1997). Iustitia interrupta. Reflexiones críticas desde la posición postsocialista, Bogotá: Siglo

8 Piedras y Cajamarca (Tolima), Tauramena (Casanare), Cabrera y Arbeláez (Cundinamarca), Cumaral (Meta), Pijao (Santander), Sucre y Jesús María (Sucre) 
del Hombre.

Garcés, M., \& Rapalino, W. (2015). La Consulta Popular como mecanismo de participación ciudadana para evitar actividades mineras. Justicia Juris, $11(1), 52-62$.

Giraldo Torres, J. (2018). Garantías del derecho fundamental a la democracia e idoneidad de los mecanismos para su disfrute: análisis a partir de la valoración de casos. Tesis de grado de Maestría. Universidad Santo Tomás. Bucaramanga. Disponible en http://hdl. handle.net/11634/12998

Habermas, J. (2005). Tres modelos de democracia. Sobre el concepto de una política deliberativa. POLIS, Revista Latinoamericana, 4(10). 1-9.

Habermas, J. (2006). Entre naturalismo y religión. Madrid: Paidós.

Hincapié, S. (2017) Extractivismo, consultas populares y derechos políticos ¿El renacimiento de la democracia local en Colombia? Reflexión política. Año 19 N. 37. 86-99.

Las consultas populares como la de Cajamarca van en contravía de la Constitución. (27 de marzo de 2017). Revista Portafolio. Recuperado de http://www.portafolio.co/economia/ gobierno/consulta-popular-de-cajamarca-vaen-contravia-de-la-constitucion-504466

Los coletazos de Cajamarca. (4 de enero de 2017). Revista Semana. Recuperado de: http://www.semana. com/economia/articulo/las-consecuenciasde-la-consulta-minera-en-cajamarca/520496
Mejía Quintana, O. (2016). Teoría Consensual del Derecho. El derecho como deliberación pública. Bogotá: Universidad Nacional de Colombia.

Mouffe, C. (2003). La paradoja democrática. Barcelona: Gedisa.

Qué significa el No de la consulta popular en Cajamarca. (3 de marzo de 2017). Revista Dinero. Recuperado de: http://www.dinero.com/edicion-impresa/ pais/articulo/cajamarca-consulta-popularcontra-anglogold-ashanti/243450

Retamozo, M. (2009). Las demandas sociales y el estudio de los movimientos sociales. Cinta Moebio, N (35), 110-127.

Rawls, J. (1990). Sobre las libertades. Barcelona: Paidós.

Rawls, J. (1995). Liberalismo político. México: Fondo de Cultura Económica y UNAM.

Sen, A. (1998). Bienestar, justicia y mercado. Barcelona: Ediciones Paidós Ibérica.

Sen, A. (2000). Desarrollo y libertad. Barcelona: Ediciones Planeta.

Simons, H. (2009). El estudio de caso: teoría y práctica. Madrid: Ediciones Morata.

Touraine, A .(2000). Derechos del hombre, representatividad, ciudadanía. En: ¿Qué es la Democracia? México. Fondo de Cultura Económica. P. 35-55. 